\title{
A PRÁTICA PEDAGÓGICA E O PROCESSO DE FORMAÇÃo DE EGRESSOS DO CURSO DE PEDAGOGIA
}

\author{
Karin Cozer de Campos \\ Universidade Estadual do Oeste do Paraná - UNIOESTE \\ karincozer@gmail.com \\ Ângela Maria Silveira Portelinha \\ Universidade Estadual do Oeste do Paraná - UNIOESTE \\ amportelinha@yahoo.com.br
}

\begin{abstract}
Resumo
Neste artigo se discute as ações desenvolvidas em projeto de extensão relacionado ao trabalho de formação continuada do grupo de egressos do curso de Pedagogia que atuaram como professores iniciantes na Educação Infantil e/ou nos Anos Iniciais do Ensino Fundamental. Para atender este objetivo apresentam-se as principais finalidades do projeto que se consistiu com a finalidade de propor intervenções, de maneira formativa e colaborativa, às práticas pedagógicas dos egressos obtendo informações necessárias para repensar os aspectos prático-organizacionais do curso de Pedagogia. As principais estratégias metodológicas envolveram encontros entre professores da universidade e os egressos com estudos e reflexões sobre a prática pedagógica, relatos orais, sistematizações escritas de experiências pedagógicas e orientações teórico-metodológicas para auxiliar a prática de ensino dos egressos e contribuir nos seus processos formativos. Os resultados do projeto evidenciam que os egressos já traziam alguma experiência no magistério proveniente das atividades de estágios não obrigatório (remunerado) realizadas durante o curso de graduação, o que lhes possibilitou ampliar a vivência e o contato com a realidade escolar. No entanto, percebeu-se que a experiência e a prática por si só não fornecem os elementos necessários para compreender, organizar e encaminhar o processo ensino-aprendizagem. Constata-se, junto aos egressos, a necessidade de uma formação teórica consistente e a importância de haver momentos coletivos para reflexões sobre a prática. Neste contexto, infere-se a necessidade da indissociabilidade das atividades de ensino, pesquisa e extensão que permeiam as práticas institucionais e as ações docentes, com a intenção de qualificar tanto o trabalho do professor universitário quanto o trabalho do professor da Educação Básica.

Palavras-chave: Professores da educação infantil. Professores das séries iniciais. Egressos. Professor iniciante. Curso de Pedagogia.
\end{abstract}

\section{TEACHING PRACTICE AND THE PROCESS OF TRAINING PEDAGOGY DEGREE GRADUATES}

\begin{abstract}
This article discusses actions developed in an extension project relating to the continuing education of a group of Pedagogy degree graduates who were working as novice Preschool and/or Infant Class Primary School teachers. It presents the main purposes of the project which consisted of proposing interventions, in a formative and collaborative manner, in the teaching practices of the novice teachers and obtaining information needed to rethink the practical and organizational aspects of the Pedagogy degree course. The main methodological strategies involved meetings between university teachers and the novice teachers with studies and reflections on teaching practice, spoken accounts, written systematization of teaching experience and theoretical/methodological guidance to aid the novice teachers' teaching practices and contribute to their formative processes. The results of the project demonstrate that the novice teachers already had some teaching experience as a result of the nonobligatory (remunerated) work placement they had done during their degree course. This had enabled them to have contact with and experience school reality. Nevertheless, experience and practice on their
\end{abstract}

Cidadania em Ação: Revista de Extensão e Cultura, Florianópolis (SC), v. 3, n.1, jan./jun. 2019. 
own do not provide the elements needed to understand, organize and proceed with the teaching/learning process. The novice teachers were found to need solid theoretical training, including the importance of having moments together to reflect on their practice. This problematizes the main needs for theoretical/methodological reinforcement and resignification in relation to the teaching practices of novice teachers recently graduated from Pedagogy degree courses, based on the principle of the indissociability of teaching, research and extension activities that pervade institutional practices and teaching actions, with the aim of qualifying both the work of the university teacher and also that of the Elementary Education teacher.

Keywords: Teachers of early childhood education. Teachers of the early grades. Graduates. Novice teacher. Pedagogy course.

\section{LA PRÁCTICA PEDAGÓgICA Y EL PROCESO DE FORMACIÓN DE EGRESOS DEL CURSO DE PEDAGOGÍA}

\section{Resumen}

Este estudio discute las acciones desarrolladas en un proyecto de extensión relacionado al trabajo de formación continua con un grupo de egresos del curso de Pedagogía que actuaban como profesores principiantes en la Educación Infantil y/o en los Años Iniciales de la Enseñanza Fundamental. Presenta las principales finalidades del proyecto que consistían en proponer intervenciones, de manera formativa y colaborativa, a las prácticas pedagógicas de los egresos obteniendo informaciones necesarias para repensar los aspectos práctico-organizacionales del curso de Pedagogía. Las principales estrategias metodológicas abarcaron encuentros entre profesores de la universidad y los egresos con estudios y reflexiones sobre la práctica pedagógica, relatos orales, sistematizaciones escritas de experiencias pedagógicas y orientaciones teórico-metodológicas para auxiliar la práctica de enseñanza de los egresos y contribuir en sus procesos formativos. Los resultados del proyecto evidencian que los egresos traían ya alguna experiencia en la docencia proveniente de las actividades de pasantía no obligatoria (remunerada) realizadas durante el curso de graduación, lo que les posibilitó la vivencia y el contacto con la realidad escolar. Sin embargo, la experiencia y la práctica por si solas no ofrecen los elementos necesarios para comprender, organizar y encaminar el proceso enseñanzaaprendizaje. Se constata, junto a los egresos, la necesidad de una formación teórica consistente y la importancia de que haya momentos colectivos para reflexiones sobre la práctica. En este contexto, problematiza las principales necesidades de complementación y resignificación teórico-metodológica relativas a la práctica pedagógica del profesor principiante, egreso del curso de Pedagogía, pautándose en el principio de la indisociabilidad de las actividades de enseñanza, pesquisa y extensión que abarcan las prácticas institucionales y las acciones docentes, con la intención de calificar tanto el trabajo del profesor universitario como el trabajo del profesor de la Educación Básica.

Palabrasclave: Formación de profesores. Egresos. Profesor principiante. Curso de Pedagogía.

Cidadania em Ação: Revista de Extensão e Cultura, Florianópolis (SC), v. 3, n.1, jan./jun. 2019. 


\section{INTRODUÇÃO}

No início da atuação profissional, no primeiro ano após a conclusão do curso de Pedagogia, percebe-se que alunos ao ingressarem em atividades práticas de ensino na escola, na Educação Infantil ou nos Anos Iniciais do Ensino Fundamental, apresentam necessidade de complementação e ressignificação da formação teórica e prática alcançada na formação inicial deste curso de licenciatura.

Como professores do curso de Pedagogia, observa-se de muitos alunos egressos, também aqui denominados como professores iniciantes, manifestações que expressam uma necessidade em retomar e dar continuidade aos estudos realizados durante a formação inicial, além do desejo de manterem-se próximos às atividades e relações acadêmicas.

Neste contexto, um grupo de egressos do curso de Pedagogia, ao iniciar suas atividades de ensino como professores se depararam com algumas situações complexas e dificuldades próprias da atividade docente. Isso conduziu a iniciativa de procurar um grupo de professores da universidade em busca de apoio e orientações metodológicas.

Enquanto professores da universidade, com o intuito de atendê-los, realizou-se algumas conversas, a princípio individuais com estes egressos, mais tarde evidenciou-se a importância de se desenvolver um trabalho que pudesse colaborar com os seus processos formativos. Vale mencionar que, por algumas vezes, durante alguns encontros com os egressos, pareceu ser situações de orientação de atividades de estágio, uma vez que os relatos que eram apresentados por eles representavam significativamente aspectos relacionados à organização do trabalho pedagógico, isto é, a necessidade de pensar como fazê-lo. Isso compôs uma das justificativas das ações do projeto de extensão desenvolvido.

Outra justificativa para a elaboração do projeto de extensão, associada ainda à necessidade apresentada por um grupo de egressos, foi o entendimento de que a universidade tem um compromisso com a escola pública e de que é possível qualificar a prática docente, desde que seja por um processo formativo problematizador, com análises e reflexões sustentadas por apoio teórico e metodológico consistentes.

Desse modo, organizou-se o projeto de extensão intitulado “A prática pedagógica e o processo de formação de egressos do curso de Pedagogia" na Universidade Estadual do Oeste do Paraná, campus de Francisco Beltrão, durante o ano letivo de 2017. A proposta foi desenvolver um trabalho de formação continuada com um grupo de alunos egressos (professores iniciantes) do curso de Pedagogia que estivessem atuando na Educação Infantil e/ou nos Anos Iniciais do Ensino Fundamental para propor intervenções às suas práticas

Cidadania em Ação: Revista de Extensão e Cultura, Florianópolis (SC), v. 3, n.1, jan./jun. 2019. 
pedagógicas de maneira formativa e colaborativa com proposições teóricas e metodológicas a partir das necessidades de complementação e ressignificação da formação teórica e prática alcançada na formação inicial.

Para desenvolver o projeto, inicialmente, definiu-se que a constituição do grupo seria de alunos egressos do curso de Pedagogia que atuassem como professores de Educação Infantil ou Anos Iniciais do Ensino Fundamental e que tivessem demonstrado interesse e necessidade de complementação e ressignificação da formação teórica e prática alcançada na formação inicial. Avaliou-se que isso garantiria ao grupo de trabalho experiências e relações comuns com o tema, neste caso, a prática pedagógica e a formação de professores.

Portanto, a constituição do grupo de trabalho do projeto se deu a partir da necessidade que um grupo de alunos egressos apresentou a alguns professores do curso de Pedagogia e que orientaram as propostas de ações do projeto. Neste caso, o grupo de trabalho foi composto por duas professoras pedagogas do curso de Pedagogia que trabalham com as disciplinas de Didática e Prática de Ensino sob a forma de Estágio Supervisionado e cinco egressos do mesmo curso (professores iniciantes). Destes egressos três eram professoras de Educação Infantil (escola pública e privada) e duas professoras nos Anos Iniciais do Ensino Fundamental (escola pública), lecionando especialmente em turmas de alfabetização.

O desenvolvimento das ações propostas pelo projeto culminou com a necessidade de socializar os resultados, por considerá-los significativos para a qualificação do processo educativo/formativo dos docentes. Assim, organiza-se esse trabalho da seguinte maneira: na primeira parte do texto, explicitam-se os princípios teórico-metodológicos que orientaram as práticas do projeto de extensão relacionando, principalmente, a uma concepção de formação de professores. Na sequência, apresentam-se as principais ações e estratégias metodológicas desenvolvidas no projeto, para, por fim, discutir os principais resultados e considerações.

\section{PRESSUPOSTOS TEÓRICO-METODOLÓGICOS QUE EMBASARAM O PROJETO DE EXTENSÃO}

Tem-se como pressuposto que a troca de experiências é formativa e a busca por alternativas e soluções de dificuldades encontradas na sala de aula é um caminho para produção de conhecimento, desde que a prática pedagógica seja objeto de reflexão e análise e considere todos os elementos que a interferem, com uma visão de "totalidade". Assim, entende-se a ação pedagógica "como um microssistema definido por uma organização social, relações interativas, formas de organização de tempos e espaços, recursos didáticos, cultivo de 
valores ético-sociais, em que os processos educativos se articulam e se explicam como elementos integradores desse sistema" (CHAMON, 2011, p. 75).

Mediante essas considerações, compreende-se que um processo formativo não ocorre de maneira espontânea, mas com rigor, sistematizações e procedimentos colaborativos. Ou seja, um "processo formativo" precisa mobilizar "[...] saberes da teoria da educação necessários à compreensão da prática docente [...] " e que possibilitem o professor investigar a própria atividade docente e constituir "os seus saber-fazer docentes, num processo contínuo de construção de novos saberes" (PIMENTA, 2011, p. 35).

Aliado a essas afirmações, há o entendimento de que a formação inicial não forma o aluno, futuro professor, por completo e em todas as áreas possíveis de atuação profissional, o que reforça a ideia de que a formação continuada é importante e necessária, apoiada, especialmente, por estudos e pesquisas. Por outro lado, há questões relacionadas à formação inicial do pedagogo que são consideradas fundamentais, como a apropriação de conceitos essenciais à atuação docente, os quais os estudantes deveriam se apropriar para terem condições de dar continuidade e aprofundamento aos seus estudos e aperfeiçoar e qualificar sua prática pedagógica constantemente. Assim, a formação continuada é importante e necessária, mas está relacionada, também, ao que o aluno conseguiu se apropriar, conceitualmente, durante a sua formação inicial.

De tal modo, entende-se que a formação de professores é constituída na relação que compreende "os docentes como sujeitos que podem construir conhecimento sobre o ensinar na reflexão crítica sobre sua atividade, na dimensão coletiva e contextualizada institucional e historicamente" (PIMENTA, 2011, p. 27).

Muitos estudos têm mostrado um avanço em relação às iniciativas de formação de professores comprometidas com a melhoria do trabalho pedagógico, o que indica que o tema tem ganhado centralidade e qualificado as discussões e pesquisas no contexto da educação.

Vale ressaltar o movimento voltado às políticas de formação de professores por ter ampliado, nas últimas décadas, o debate e as reflexões forjando a elaboração de uma série de indicativos relativos à necessidade de articular as instituições formadoras e os sistemas de ensino num processo orgânico e contínuo de formação.

Embora esteja assegurado pela Lei de Diretrizes e Bases da Educação Nacional (LDB), n. 9.394/96, art., 62 §1 ${ }^{\circ}$, o regime de colaboração entre a União, o Distrito Federal, os Estados e os Municípios, na promoção da formação inicial, continuada e a capacitação dos profissionais de magistério, ainda temos de avançar nos modelos formativos destinados aos professores.

Cidadania em Ação: Revista de Extensão e Cultura, Florianópolis (SC), v. 3, n.1, jan./jun. 2019. 
É recorrente nos depararmos com a oferta de cursos de curta duração organizados por áreas de conhecimento ou por aspectos metodológicos. Isso reflete a dissociação entre a forma e o conteúdo e a descontinuidade do processo formativo acarretando poucas alterações nas práticas pedagógicas.

Desse modo, ainda é um desafio propor atividades formativas que consigam dar conta da complexidade que o processo de formação docente envolve, especialmente fazer a relação adequada entre teoria e prática, sem priorizar mais uma do que outra, mas de pensá-las conjuntamente. Uma vez que a prática pedagógica "não pode ser isenta de conhecimentos teóricos", da mesma forma que estes conhecimentos quando relacionados à prática "ganham novos contornos e significados na interação com a realidade escolar" (CHAMON, 2011, p. 74).

Para Chamon (2011, p. 74), no processo de formação docente, tanto a inicial quanto a continuada, é importante articular o ensino e a aprendizagem para compreender que "a mediação pedagógica entre quem ensina e quem aprende constitui-se como um processo que deve ser aprendido e apropriado em seus saberes e fazeres.”.

Para a autora, isso é mais uma consideração que deve ser observada nas propostas de formação de professores, e que também se tornou referência na elaboração e desenvolvimento do projeto de extensão com os egressos do curso de Pedagogia.

Tais considerações embasaram as ações do projeto de extensão, que buscou contribuir ao processo formativo dos egressos (professores iniciantes) e do mesmo modo contribuir com a melhoria da escola pública.

\section{PROCEDIMENTOS METODOLÓGICOS DO PROJETO DE EXTENSÃO}

O projeto de extensão "A prática pedagógica e o processo de formação de egressos do curso de Pedagogia" foi desenvolvido a partir de encontros entre as professoras pedagogas da universidade e os egressos, e ocorreram quinzenalmente durante o ano letivo de 2017. As atividades do projeto tiveram como principais procedimentos metodológicos relatos orais e escritos de situações e experiências da prática pedagógica; orientações e proposições teóricas e metodológicas às práticas pedagógicas relatadas nos encontros; leitura e estudo de materiais relacionados à temática do projeto: a prática pedagógica e a formação de professores; sistematizações dos principais aspectos da prática pedagógica, relatados e problematizados nos encontros e reflexão e avaliação sobre a experiência dos egressos com o projeto.

Durante os encontros, procurou-se sempre ouvir o que as professoras iniciantes (egressos) tinham a relatar sobre suas práticas pedagógicas. A partir dos relatos das

Cidadania em Ação: Revista de Extensão e Cultura, Florianópolis (SC), v. 3, n.1, jan./jun. 2019. 
professoras iniciantes, e como forma de contribuir aos seus processos formativos, buscou-se orientar-lhes teórica e metodologicamente.

Os relatos orais se tornaram uma estratégia metodológica importante e se destacaram nos encontros pela necessidade que as professoras iniciantes tinham de falar e relatar as situações que estavam vivenciando em sala de aula, sobretudo as dificuldades que enfrentavam com seus alunos e que estavam relacionadas, principalmente, ao ensino e aprendizagem. Por isso, uma escuta atenta e interessada dos relatos das professoras iniciantes se tornou uma premissa importante nos encontros. Assim, primeiramente, ouvia-se as professoras para depois discutir sobre os relatos e pensar proposições metodológicas.

Nesta tarefa, de escuta e de pensar proposições, todos do grupo se envolviam. Isto é, não eram apenas as professoras pedagogas da universidade que pensavam ou sugeriam estratégias metodológicas, as outras professoras iniciantes (egressos) também se envolviam às discussões e problemáticas trazidas. Isso garantiu ao projeto uma rica troca de experiências e saberes entre os envolvidos, porque mesmo aqueles que não estavam passando pela mesma situação relatada, puderam, pela escuta do relato do outro, ter uma experiência de aprendizado.

Enfatiza-se que a intenção do projeto não era interferir na prática pedagógica das professoras iniciantes, mas de poder problematizar coletivamente suas experiências em sala de aula, orientar-lhes e pensar estratégias metodológicas que lhes auxiliassem no cotidiano escolar e, principalmente, atender às necessidades trazidas pelas professoras.

Neste contexto, também se elaborou instrumentos didáticos que pudessem auxiliar as professoras. Como exemplo, a elaboração de um "instrumento diagnóstico" que foi organizado para auxiliar as professoras na avaliação da aprendizagem e desenvolvimento de seus alunos. O instrumento abordava as principais dimensões formativas das diferentes áreas do conhecimento da Educação Infantil e dos Anos Iniciais do Ensino Fundamental (Linguagem, Conhecimento lógico-matemático, Ciências Sociais e Ciências Naturais). Para cada uma das dimensões formativas foi sugerido um roteiro de conhecimentos e capacidades que poderiam ser desenvolvidas pelas crianças para serem avaliadas pelas professoras e, assim, se tornar um instrumento diagnóstico de referência para elas identificarem o desenvolvimento e a aprendizagem de seus alunos.

Assim, a partir dos relatos das professoras iniciantes, e como forma de contribuir aos seus processos formativos, buscou-se orientar-lhes teórica e metodologicamente. Como exemplo, apresenta-se um "instrumento diagnóstico" proposto às professoras iniciantes para realizarem com seus alunos e poderem identificar aspectos mais pontuais da aprendizagem e

Cidadania em Ação: Revista de Extensão e Cultura, Florianópolis (SC), v. 3, n.1, jan./jun. 2019. 
desenvolvimento deles.

\begin{tabular}{|c|c|}
\hline \multicolumn{2}{|r|}{ ROTEIRO PARA UM DIAGNÓSTICO DAS CRIANÇAS } \\
\hline \multicolumn{2}{|l|}{ Nome da criança e idade } \\
\hline Dimensões formativas & Conhecimentos e capacidades desenvolvidas \\
\hline Leitura & $\begin{array}{l}\text { Diferencia letras de números e desenhos, conhece e reconhece as letras do alfabeto, } \\
\text { lê (desenhos, imagens, rótulos, tipos de letras, palavras curtas, frases, textos), faz } \\
\text { leitura oral com fluência, interpreta o que lê, consegue contar o que lê com detalhes, } \\
\text { dificuldades na leitura (quais). }\end{array}$ \\
\hline Escrita & $\begin{array}{l}\text { Faz registros escritos (desenhos, rabiscos, figuras, nome, palavras, frases, textos), } \\
\text { caligrafia, cópia do quadro sem erros, troca de letras, utiliza pontuação e } \\
\text { acentuação, escreve com coerência e coesão (frases, textos), dificuldades na escrita } \\
\text { (quais). }\end{array}$ \\
\hline $\begin{array}{l}\text { Conhecimento lógico- } \\
\text { matemático }\end{array}$ & $\begin{array}{l}\text { Tem noções de quantidade (menor/maior, mais/menos, muito/pouco), faz } \\
\text { classificação de elementos (por cor, tamanho, forma), conhece e reconhece os } \\
\text { números, faz contagem oral, faz cálculo mental (simples, complexo), resolve } \\
\text { sentenças matemáticas envolvendo as quatro operações, consegue resolver } \\
\text { problemas, quais as dificuldades. }\end{array}$ \\
\hline $\begin{array}{c}\text { Ciências Sociais } \\
\text { (História e Geografia) }\end{array}$ & $\begin{array}{l}\text { Relaciona os conceitos de História e Geografia com a realidade: tem noções de } \\
\text { tempo/duração/sucessão (agora, antes, depois, ontem, hoje, amanhã, dia, noite), } \\
\text { noções de espaço/localização (perto/longe, em cima/embaixo/lado/frente/atrás, } \\
\text { identifica pontos de referência, percurso, trajeto), identifica/nomeia os membros da } \\
\text { família/escola. }\end{array}$ \\
\hline Ciências Naturais & $\begin{array}{l}\text { Reconhece os diversos fenômenos naturais, estabelece a relação entre ação do } \\
\text { homem e alteração da natureza, noções gerais do corpo humano, saúde, alimentos, } \\
\text { cuidados essenciais com o ambiente, noções de desenvolvimento sustentável. }\end{array}$ \\
\hline
\end{tabular}

Fonte: Elaboração própria das autoras.

A indicação de alguns conhecimentos e capacidades não significa dizer que são apenas estes que constituem as dimensões formativas. A intenção é apresentar alguns exemplos para auxiliar os professores iniciantes na observação do desenvolvimento e aprendizagem de seus alunos.

Com base nesse instrumento, as professoras iniciantes realizaram uma avaliação diagnóstica sobre a aprendizagem e o desenvolvimento de cada um de seus alunos em sala de aula. Este instrumento diagnóstico foi sugerido porque observou-se que as professoras iniciantes, algumas vezes, quando relatavam as dificuldades de aprendizagem de seus alunos tinham dificuldade de apontar objetivamente quais eram as dificuldades ou, também, porque não tinham, até aquele momento, realizado um diagnóstico mais preciso sobre o desenvolvimento dos alunos. Além disso, entende-se a avaliação diagnóstica como uma fase anterior ao planejamento de ensino do professor que o auxilia a conhecer melhor a realidade em que atuará e definir as intervenções necessárias (FARIAS, 2011).

A prática da escrita também foi uma das atividades desenvolvidas no projeto de extensão. As professoras iniciantes foram orientadas a produzirem escritas sobre suas

Cidadania em Ação: Revista de Extensão e Cultura, Florianópolis (SC), v. 3, n.1, jan./jun. 2019. 
experiências pedagógicas, como exemplo, a situação em que o enunciado "como ensino e por que ensino" orientou as professoras a escrever. A intenção era de que as professoras iniciantes pudessem se colocar na escrita como sujeitos ativos do processo de ensino aprendizagem, visto que, algumas vezes, as professoras relatavam situações de dificuldades de ensino com seus alunos, mas não conseguiam se colocar também como sujeitos participantes desse processo. Ou seja, as professoras perceberem que elas também teriam de rever e readequar suas práticas, ao considerar-se que, muitas vezes, as estratégias metodológicas adotadas pelo professor não atendem a necessidade de aprendizagem da criança.

A proposta de as professoras iniciantes produzirem escritas potencializou a elas a oportunidade de poderem refletir sobre suas próprias práticas de ensino, sobretudo quando foram conduzidas a escrever como ensinavam e por que ensinavam. Isto é, as professoras iniciantes precisaram rememorar suas experiências em sala de aula, pensar sobre elas e olharem para si próprias como professoras e exporem suas percepções pela escrita.

A análise desse material, da escrita das professoras iniciantes, possibilitou compreender a prática pedagógica delas e identificar algumas teorias implícitas nas ações docentes. Isso impôs o desafio de refletir coletivamente sobre as práticas institucionais e ações docentes e reorganizar os encaminhamentos didático-pedagógicos. Nesse sentido, vale a elucidativa de Contreras (2002, p.75) quando afirma que:

A relação entre as qualidades das atuações profissionais e as exigências da prática docente reflete também a dialética entre, por um lado, condições e restrições da realidade educativa e, por outro, formas de viver e desenvolver a profissão enquanto atitudes e destrezas postas em jogo pelos membros concretos da profissão.

Como forma de qualificar a formação dos egressos, foi proposto também momentos de estudos e reflexões sobre a prática pedagógica. Para isso, buscou-se referências que estivessem relacionadas às necessidades apresentadas pelas professoras iniciantes durante os encontros. O propósito era ter o estudo como fundamento para pensar sobre as problemáticas trazidas e garantir que a formação do projeto de extensão primasse pela unidade entre teoria e prática.

O estudo compôs uma das atividades do projeto de extensão e potencializou unificar a relação teoria e prática. No entanto, é importante dizer que a proposta do projeto não era desenvolver uma formação continuada a partir de estudos teóricos. A proposta era ter as experiências práticas de sala de aula trazidas pelas professoras iniciantes, e que poderiam se tornar ricas problemáticas, como ponto de partida para então discuti-las na coletividade com referências teóricas que pudessem auxiliar o grupo envolvido pensar em orientações 
metodológicas e auxiliar o professor iniciante. Uma das premissas do projeto de extensão era de que a experiência de formação continuada pela qual as professoras iniciantes estavam envolvidas fosse diferente da formação inicial (graduação) para enfatizar principalmente as situações reais de ensino e o contexto escolar em que estivessem inseridas.

Os encontros foram pensados para ocorrer no coletivo com todos os egressos (professores de Educação Infantil e Anos Iniciais do Ensino Fundamental) e professoras da universidade. No entanto, ocorreu situações em que algumas professoras iniciantes apontaram necessidade de orientações metodológicas específicas que exigiu que os encontros fossem reorganizados. Assim, foi necessário realizar encontros individualizados com algumas professoras iniciantes para poder atender mais especificamente as suas necessidades, especialmente as que se relacionavam com as práticas de alfabetização e que têm uma especificidade de ensino diferente da Educação Infantil. Embora houvessem os encontros individualizados, os encontros coletivos sempre foram garantidos pela experiência educativa que significavam e também por solicitação das próprias professoras iniciantes que avaliavam como positivas e ricas as trocas de experiências que ocorriam quando estavam em grupo.

Enfatiza-se que os encontros entre as professoras da universidade e os egressos potencializaram aprendizados importantes que certamente indicaram repensar aspectos da prática pedagógica, tanto dos egressos, professores iniciantes, quanto do curso de Pedagogia. Adiante no texto, tratar-se-á mais sobre isso ao se discutir sobre as principais considerações do desenvolvimento do projeto.

\section{RESULTADOS E CONSIDERAÇÕES FINAIS}

$\mathrm{Na}$ elaboração das atividades do projeto de extensão, o principal objetivo pautou-se nas contribuições colaborativas relativas ao processo formativo dos egressos do curso de Pedagogia (professores iniciantes). Do mesmo modo, também, por meio dos relatos e das trocas de experiências pedagógicas entre os sujeitos envolvidos no projeto, observou-se que as informações ajudam a pensar proposições que qualificassem o curso de Pedagogia.

Neste sentido, destaca-se que as vivências do projeto de extensão sinalizaram aspectos da prática pedagógica que ajudam a pensar sobre o curso de Pedagogia. No entanto, ainda não é possível, pela experiência com este projeto, indicar pontualmente todos os aspectos formativos que seriam necessários rever no curso.

Por outro lado, foi possível identificar algumas evidências que indicam resultados significativos decorrentes das ações desenvolvidas no projeto de extensão. Dentre elas, o 
projeto evidencia claramente a necessidade que os egressos do curso têm em retomar, complementar e ressignificar sua formação teórica e prática alcançada na formação inicial deste curso de licenciatura. Uma das constatações é de que isso está muito relacionado ao momento em que o egresso inicia suas atividades profissionais na escola. Isto é, ao se deparar com a tarefa de ter que assumir-se como professor regente de sala de aula e atender a todas as atribuições que isso o envolve, o egresso sente-se inseguro e não preparado o suficiente para todas as situações que o contexto escolar lhe envolve, incluindo todas as suas diversidades. Por isso, reconhece-se a necessidade de os egressos continuarem inseridos em processos de formação e sendo assim infere-se a necessidade de estudos e compartilhamento de práticas com vista a potencializar a formação de professores da educação infantil e ensino fundamental no que aproxima a realidade dos egressos do curso de Pedagogia.

Os relatos trazidos pelas professoras iniciantes confirmam principalmente, as dificuldades que elas manifestaram para organizar seu trabalho pedagógico, sobretudo com relação ao planejamento de ensino, sequência didática, processos de alfabetização e as dificuldades de aprendizagem das crianças.

A organização do trabalho pedagógico ficou evidente como uma das maiores dificuldades apresentadas pelas professoras. Percebeu-se que elas tinham objetivos de trabalho e muito interesse em desenvolver atividades pedagógicas que fossem críticas e coerentes às necessidades de aprendizagem das crianças. No entanto, as professoras relatavam sentirem-se "perdidas". Destaca-se esta expressão, própria dos relatos delas, porque era assim que elas, muitas vezes, manifestaram suas dificuldades, com expressões como essa que não apenas revelava como elas se sentiam como também apresentava um panorama do contexto escolar em que estavam inseridas.

Sobre isso, os relatos das professoras indicaram a falta de orientações pedagógicas na escola que lhes auxiliassem a organizar o trabalho pedagógico. Dentre algumas realidades em que estavam inseridas, essa falta de orientação se justificava pela falta de profissionais na escola para desempenhar tal tarefa ou pela própria dificuldade desses profissionais em ajudálas. Neste caso, então, as razões envolviam a falta de preparação das equipes pedagógicas das escolas ou, em algumas situações, o entendimento de que o professor mesmo sendo recémformado precisa dar conta de suas atribuições.

Implícito a esses relatos encontra-se uma determinada concepção de formação, entendida esta como um processo pronto e acabado, que se encerra no momento da conclusão do curso. No entanto, entende-se a formação como um processo permanente e contínuo, cuja ação docente se respalda na tríade ação-reflexão-ação. Significa dizer, que a atividade de

Cidadania em Ação: Revista de Extensão e Cultura, Florianópolis (SC), v. 3, n.1, jan./jun. 2019. 
ensinar constitui-se como formativa quando contempla ações metódicas e intencionais aliadas à pesquisa, ao aprofundamento dos fundamentos teórico-metodológicos e as reflexões coletivas sobre a prática educativa.

Com relação às dificuldades de aprendizagem das crianças, observou-se que as professoras iniciantes as relacionavam a aspectos comportamentais das crianças, deixando de considerar os processos de desenvolvimento próprios da criança e a sua relação com o ambiente e a cultura escolar, no qual a criança, especialmente da Educação Infantil, ainda está se inserindo, como, por exemplo, a atenção e o envolvimento nas atividades propostas. Além disso, identificou-se a dificuldade de as professoras olharem para suas próprias práticas de ensino e identificar a necessidade de fazer readequações e que indica que, talvez, a dificuldade não estava na aprendizagem das crianças, mas nas estratégias metodológicas utilizadas.

As ações desenvolvidas no projeto revelam resultados no que tange aos significados e ressignificados relativos à prática docente. Os professores iniciantes, egressos do curso de Pedagogia, já contavam com uma experiência no magistério proveniente do estágio não obrigatório (estágio remunerado). Tal experiência possibilitou a vivência e o contato direto com a realidade da escola e instituições de Educação Infantil. No entanto, os egressos manifestam nos encontros que a experiência e a prática por si só não fornecem os elementos necessários para compreender, organizar e encaminhar o processo ensino-aprendizagem.

Assim, expressam a necessidade de discutir no coletivo questões ligadas ao planejamento, avaliação, desenvolvimento infantil, como também o processo de alfabetização. Constituir-se profissional da área da educação, nesse caso específico professores para a Educação Infantil e Anos Iniciais do Ensino Fundamental, exige uma sólida formação teórica acompanhada da relação de unidade teoria e prática. A atuação direta com o exercício da docência tem mobilizado nos egressos reflexões sobre sua formação inicial e a necessidade da formação continuada. Desse modo, avaliaram de maneira positiva as ações desenvolvidas pelo projeto destacando o compromisso social da Universidade com a melhoria da educação.

Cidadania em Ação: Revista de Extensão e Cultura, Florianópolis (SC), v. 3, n.1, jan./jun. 2019. 


\section{REFERÊNCIAS}

BRASIL. Lei de Diretrizes e Bases da Educação Nacional. Lei nº 9.394 de 20 de dezembro de 1996.

CHAMON, M. O instituído e o instituinte nos cursos de formação de professores: desafios da contemporaneidade. Formação Docente. Belo Horizonte, v. 4, n. 4, p. 71-80, jan./jul., 2011.

CONTRERAS, J. A autonomia dos professores. São Paulo: Cortez, 2002.

FARIAS, I. M. S. et al. Didática e docência: aprendendo a profissão. $3^{\mathrm{a}}$ ed. Brasília: Liber Livro, 2011.

PIMENTA, S.G. Pesquisa-ação critico-colaborativa: construindo seu significado a partir de experiências na formação e atuação docente. In: PIMENTA, S.G.; GHEDIN, E.; FRANCO, M.A. (Orgs). Pesquisa em educação. Alternativas investigativas com objetos complexos. São Paulo: Edições Loyola Jesuítas, 2011. 